\title{
Sex pheromones in marine polychaetes: volatile organic substances (VOS) isolated from Arenicola marina
}

\author{
J. D. Hardege ${ }^{1, *}$, M. G. Bentley ${ }^{1}$, M. Beckmann ${ }^{2}$, C. Müller $^{2}$ \\ ${ }^{1}$ Gatty Marine Laboratory, University of St. Andrews, St. Andrews KY16 8LB, United Kingdom \\ ${ }^{2}$ Institute for Chemistry and Biology of the Marine Environment, University of Oldenburg, D-26160 Oldenburg, Germany
}

\begin{abstract}
Volatile organic substances (VOS) were extracted from the coelomic fluid of gravid specimens of the lugworm Arenicola marina through the use of using a closed loop stripping technique and analysed via coupled gas chromatography-mass spectroscopy. VOS detectable in coelomic fluid of mature specimens include aldehydes, n-alkanes, methyl-alkanes, terpenes and ketones. The bouquet of compounds is very similar to nereid volatiles that have been recently described as having sex pheromonal activity. One of the major constituents is the ketone 5-methyl-3-heptanone, the sex pheromone of Platynereis dumerilii and Nereis succinea. Behavioural bioassays with gravid specimens produced no evidence that this substance has any pheromonal function in A. marina. Samples taken at monthly intervals showed an increase in the content of VOS in the coelomic fluid of both sexes during maturation with 1 major peak, 2-ethyl-hexanol, representing up to $50 \%$ of the total amount of VOS in spawning male lugworms. Behavioural assays with ripe females established the existence of a chemical cue inducing the burrow irrigation behaviour during which sea water is pumped through the burrows. This behaviour ensures transport of spermatozoa from the water column into the tube inhabited by the female and increases fertilization success by minimising the dilution effects of the incoming tide. The VOS extract obtained from male spawning water had biological activity in eliciting the 'pumping' behaviour in females, with 16 of 24 worms irrigating continuously upon exposure, whilst controls showed no increase of activity, with 'pumping' occurring at 30 to 40 min intervals
\end{abstract}

KEY WORDS: Arenicola manina Spawning Pheromones · Volatile organic substances

\section{INTRODUCTION}

Although chemical communication via sex pheromones has been proposed in numerous marine organisms, complete chemical characterisation of these cues have been attained only extremely rarely (Agosta 1992). By far the best examined system is the pheromonal control of sperm activation and attraction in marine brown algae (Jaenicke 1977, Müller et al. 1982). In the past 20 years some 50 species of brown alga have been examined and the gamete attractants isolated and identified (Jaenicke \& Boland 1982) as

- Present address: PABIO, University of Wales, 50 Park Place, Cardiff CF1 3TL, UK. E-mail: sabjdh@cardiff.ac.uk lipophilic volatile terpenes, most of which have elevencarbon structures. Recent publications describe the biosynthetic pathways of the signal molecules (Neumann \& Boland 1990) and their absolute configuration (Boland et al. 1989) and characterise the pheromone receptors (Boland 1989, Boland et al. 1989). Lipophilic volatile signal molecules are also involved in the gamete attraction, and Coll et al. (1995) identified epithunbergol as the sperm attractant in Lobophytum crassum. Finally, sirenin, a close relative to 2 -carene, is the gamete attractant in the water mould Allomyces macrogynus (Machlis et al. 1966, Pommerville 1988).

Environmental and endocrine factors alone are not always sufficient to ensure simultaneous release of gametes in broadcast spawning individuals of a given population, and it has been shown that, in nereid poly- 
chaetes for example, sex pheromones provide an additional fine tuning of reproduction (Boilly-Marer \& Lassalle 1978). In nereids, pheromones control the release of gametes as well as the stimulation of a specific reproductive behaviour, the 'nuptial dance'. In Platynereis dumerilii, the nuptial dance is triggered by a volatile ketone, 5-methyl-3-heptanone (Zeeck et al. 1988). There exist 2 enantiomers of this molecule that have sex specific activity, and the action of which results in the recognition of the partner of the opposite sex, the performance of the nuptial dance and the initial release of a small amount of gametes by males (Zeeck et al. 1992). This nuptial dance behaviour is then followed by the release of gametes of both partners due to further pheromonal signals of a hitherto unknown chemical nature (Hardege 1992).

Spawning in the lugworm Arenicola marina occurs following maturation of the gametes in both sexes. More specifically, this involves the activation and motility acquisition in spermatozoa of males, and reinitiation of meiosis in oocytes of females. Maturation and subsequent spawning is controlled by maturation/ spawning hormones from the prostomium (Howie 1961b, Bentley et al. 1990, Pacey \& Bentley 1992). When released from the prostomial region of females, the hormone initiates the progression of oocytes from the first meiotic prophase to the meiotic metaphase, in which condition fertilization can take place (Meijer 1979). The chemical nature of this germinal-vesiclebreakdown-inducing hormone remains unknown but progress has been made recently in the identification of the male spawning hormone. The active compound that activates spermatozoa of males and initiates the release of the spermatozoa is a polyunsaturated fatty acid, 8,11,14-eicosatrienoic acid (Bentley et al. 1990, Pacey \& Bentley 1992). Whilst information is available on the chemical nature of at least part of the endocrine pathway causing spawning (in males) there is no information on the possible role of environmental cues or chemical signals that may control the timing of gamete release in the field. The possible influence of the first frost of winter has now been discounted (see Howie 1984, Bentley \& Pacey 1992). What is evident, however, is that certain populations show a marked degree of spawning synchrony (Howie 1959, Duncan 1960 , Bentley \& Pacey 1992). Although exposed to the same or very similar environmental conditions, 2 populations of A. marina inhabiting neighbouring beaches at $\mathrm{St}$. Andrews (Scotland) have markedly different spawning dates (Hardege \& Bentley unpubl.). A proportion of individuals maintained in the laboratory under constant temperature and daylength conditions and in the absence of moonlight spawn at exactly the same time as their field counterparts (Howie 1963). Thus, endocrine factors may also trigger the spawning activity of a given population. In this study we investigated the role of volatile organic substances (VOS) as chemical signals in the timing of epidemic mass spawning of $A$. marina.

\section{MATERIALS AND METHODS}

Collection and maintenance of worms. Field collection of Arenicola marina was commenced in July (14 wk prior to the natural spawning period in the field). Individuals at varying stages of sexual maturity were collected at $2 \mathrm{wk}$ intervals during periods of low water of spring tides from the beach at East Sands, St. Andrews. The animals were transported back to the laboratory, sexed by light microscopical observation of gametes taken from the coelomic cavity, and placed individually in plastic containers filled with sea water $(200 \mathrm{ml})$. The animals were maintained for periods of up to $2 \mathrm{wk}$ in the laboratory at a constant $10^{\circ} \mathrm{C}$ under natural daylength conditions. As a test of maturity, male A. marina worms ( $\mathrm{n}=10$ ) were injected with $13 \mu \mathrm{g} \mathrm{g}^{-1}$ body weight of the spawning hormone 8,11,14-eicosatrienoic acid (Table 1) as described by Pacey \& Bentley (1992) prior to all extractions of VOS or behavioural experiments. 8,11,14-eicosatrienoic acid was obtained from Sigma Chemical Co., and $1 \times$ $10^{-2} \mathrm{M}$ stock solutions were prepared in HPLC-grade methanol. For use in assays, aliquots of these stock solutions were diluted 100 -fold to give a final concentration of $10^{-4} \mathrm{M}$. Females were injected with prostomium homogenate (1 prostomium equivalent per female) which causes spawning in fully mature specimens (Table 1) (Howie 1961a, b, Pacey \& Bentley 1992).

Extraction and analysis of volatile organic sub. stances. At monthly intervals (see Fig. 1) $10 \mathrm{ml}$ of coelomic fluid were removed from 2 to 3 specimens with a syringe for subsequent extraction of VOS. VOS from standards as well as samples from Arenicola manina were concentrated by using a closed loop strip-

Table 1. Induction of spawning in Arenicola marina by injection of 8,11,14-eicosatrienoic acid (males: $13 \mu \mathrm{g} \mathrm{g}^{-1}$ body weight) and prostomium homogenate (females, 1 prostomium equivalent per worm). $(+)$ weak positive response. SD in parentheses

\begin{tabular}{|lcccc|}
\hline Date & Males & $\begin{array}{c}\text { Reaction } \\
\text { time (min) }\end{array}$ & Females & $\begin{array}{c}\text { Reaction } \\
\text { time (min) }\end{array}$ \\
\hline 15 Jul 93 & $-0 / 10$ & - & $-0 / 10$ & - \\
15 Aug 93 & $++) 1 / 10$ & 90 & $-0 / 10$ & - \\
15 Sep 93 & $+6 / 10$ & $75(14)$ & $-0 / 10$ & - \\
15 Oct 93 & $+8 / 10$ & $65(15)$ & $+5 / 10$ & $480(180)$ \\
30 Oct 93 & $+14 / 15$ & $60(10)$ & $+6 / 9$ & $320(120)$ \\
\hline
\end{tabular}


ping technique (CLS) developed by Grob \& Zürcher (1976). This design includes a 'Hersch-spiral' introduced by Gassmann (Biologische Anstalt Helgoland, Germany) for extraction of algal pheromones (Müller \& Schmid 1988) and also used by Zeeck et al. (1988) for extraction of nereid sex pheromones. Prior to extraction of biological samples, the recovery of synthetic volatile standards from the charcoal filter, after extraction with the CLS apparatus, was measured. Stock solutions of synthetic standards were prepared in methanol. A total of $50 \mathrm{\mu g}$ per component was transferred into the CLS apparatus (filled with Millipore water) and extracted for $8 \mathrm{~h}$ at $20^{\circ} \mathrm{C}$. After extraction, standards were desorbed from a $1.5 \mathrm{mg}$ charcoal filter with $50 \mu \mathrm{l}$ of dichloromethane and analysed by gas chromatography. Recovery of 28 standards, representing ketones, aldehydes and n-alkanes, was greater than $80 \%$. Exceptions were 1-hexadecane and 1heptadecane, which were recovered at 71 to $73 \%$.

For extraction of VOS, gametes were first removed from coelomic fluid samples by centrifugation at $13500 \mathrm{rpm}$ and the supernatant was then filtered through a sterile filter (Whatman, $0.2 \mu \mathrm{m}$ ). Samples and synthetic standards were diluted with sterilised sea water to give a final volume of $800 \mathrm{ml}$ and volatile compounds were transferred into the gas phase using a CLS apparatus. VOS were trapped on $5 \mathrm{mg}$ activated charcoal filters, desorbed with methanol $(20 \mu \mathrm{ll})$ and in a second step with dichloromethane $(20 \mu \mathrm{l})$. The extraction procedure was performed at $20^{\circ} \mathrm{C}$ for $6 \mathrm{~h}$. Prior to every extraction of biological material the CLS system was calibrated and adjusted by using a hydrocarbon standard mixture $\left(\mathrm{C}_{8}\right.$ to $\left.\mathrm{C}_{17}\right)$.

In order to examine sources of volatile compounds detected in biological samples, control extractions were done with laboratory air $(24 \mathrm{~h}$ extraction $=300 \mathrm{l}$ air) and sea water Control extractions of sea water samples were also analysed prior to every extraction of biological material. As described by Hardege (1992) for various sea water samples from the North Sea, coupled gas-chromatography/mass-spectroscopic analysis showed these compounds to be mainly n-alkanes and benzenes.

Extraction of non-volatile, water soluble cues. An extract of water soluble, non-volatile compounds of the coelomic fluid of Arenicola marina was prepared from gravid females collected from the Eden Estuary in $1994.10 \mathrm{ml}$ of coelomic fluid was removed from gravid females with a syringe, centrifuged at $13500 \mathrm{rpm}$ for 5 min and the supernatant used for extraction. Sterile filtration (Whatman, $0.2 \mu \mathrm{m}$ ) was followed by $10 \mathrm{kDa}$ and $1 \mathrm{kDa}$ filtration (Amicon Ultrafiltration, stirred cell with nitrogen pressure at $50 \mathrm{psi}$ ) and the resulting solution extracted twice with $10 \mathrm{ml}$-hexane. The aqueous phase was than lyophilized (Genevac CVP
100), washed twice with $2.5 \mathrm{ml}$ methanol and the resulting residue taken up in $1 \mathrm{ml}$ Millipore water and used for bioassays.

Gas chromatography and mass spectroscopy. The second step of the characterisation of volatile organic compounds is analytical gas chromatography, which was performed by using a PYE 104 gas chromatograph fitted with a fused silica capillary column (DB-5, $30 \mathrm{~m}, 1 \mu \mathrm{m}$ film, $0.35 \mathrm{~mm}$ ID) using a temperature gradient from $40^{\circ} \mathrm{C}$ (5 min) to $200^{\circ} \mathrm{C}$ at $3^{\circ} \mathrm{C} \mathrm{min}^{-1}$ except in Fig. 6 where a gradient of $5^{\circ} \mathrm{C} \mathrm{min}^{-1}$ was used. Mass spectrometry was carried out at the Institute for Chemistry and Biology of the University of Oldenburg, Germany. The GC-MS measurements were performed on a Finnigan Magnum Ion-trap system fitted with a DB- 5 capillary column using a temperature gradient from $40^{\circ} \mathrm{C}(1 \mathrm{~min})$ to $200^{\circ} \mathrm{C}$ at $3^{\circ} \mathrm{C}$ $\mathrm{min}^{-1}$. Data were recorded and interpreted using the Finnigan Magnum data-system software.

Biological assay methodologies. Two different types of bioassays were used in order to examine the effects of VOS on ripe Arenicola marina: (1) Worms were cultured individually in polystyrene boxes (200 $\mathrm{ml}$ water) and the culture water was changed daily. All substances under investigation were added with a micro pipette into the culture water and behavioural changes monitored continuously for $60 \mathrm{~min}$ and thereafter controlled at $30 \mathrm{~min}$ intervals. In every experiment a group of worms was treated by adding sea water as a control, and for experiments with VOS extracts a second control group was exposed to the amount of solvent used in the extracts. (2) Ripe individuals were placed and cultured for at least $24 \mathrm{~h}$ prior to any experiment in an aquarium with glass $U$ shaped tubes as described by Bentley \& Hardege (1996). The aquarium was connected to the laboratory flow-through sea water system in order to supply fresh running sea water. The tidal cycle was simulated by adjusting the flow rate, and substances under investigation were added either to the sea water supply or individually to each specimen within the Utubes. As the aquarium was divided into 2 separate chambers, water flow between the sides was via the U-tubes. This apparatus was used in order to examine the influence of VOS (controls, coelomic fluid, gamete-containing culture water, etc.) as well as the influence of tidal currents on the pumping activity (burrow irrigation) of individual worms in the tubes. To monitor pumping activity of ripe worms, the incoming sea water (of one compartment of the Utube tank) used during the experiment was coloured by brilliant blue FCF food colouring. This allowed water flow that was a result of pumping activity to be monitored visually. Frequency and duration of pumping activity induced by VOS were recorded and compared with those elicited by controls. 


\section{RESULTS}

\section{Behavioural assays}

Recent investigations into the spawning behaviour of Arenicola marina have provided evidence for the existence of sex pheromones. Exposure of gravid animals to sea water into which gametes had been released induced spawning in both sexes but the chemical nature of these cues remains unknown (Hardege \& Bentley unpubl.). As shown in Fig. 1, sea water into which female $A$. marina had released eggs induced males (at around the normal spawning time in the field) to release gametes. This indicates that a waterborne chemical signal is involved. Removal of eggs via centrifugation established that this biological activity is associated with the coelomic fluid (supernatant) whilst eggs induced only very little activity. The chemical cue appears to have a very short half-life because egg-containing sea water collected from females which had spawned during the previous night failed to induce any reaction in males.

Sea water samples obtained from culture of isolated gravid females failed to induce males to release gametes ( 2 of 15 and 2 of 9 on 28 and 29 October 1993,

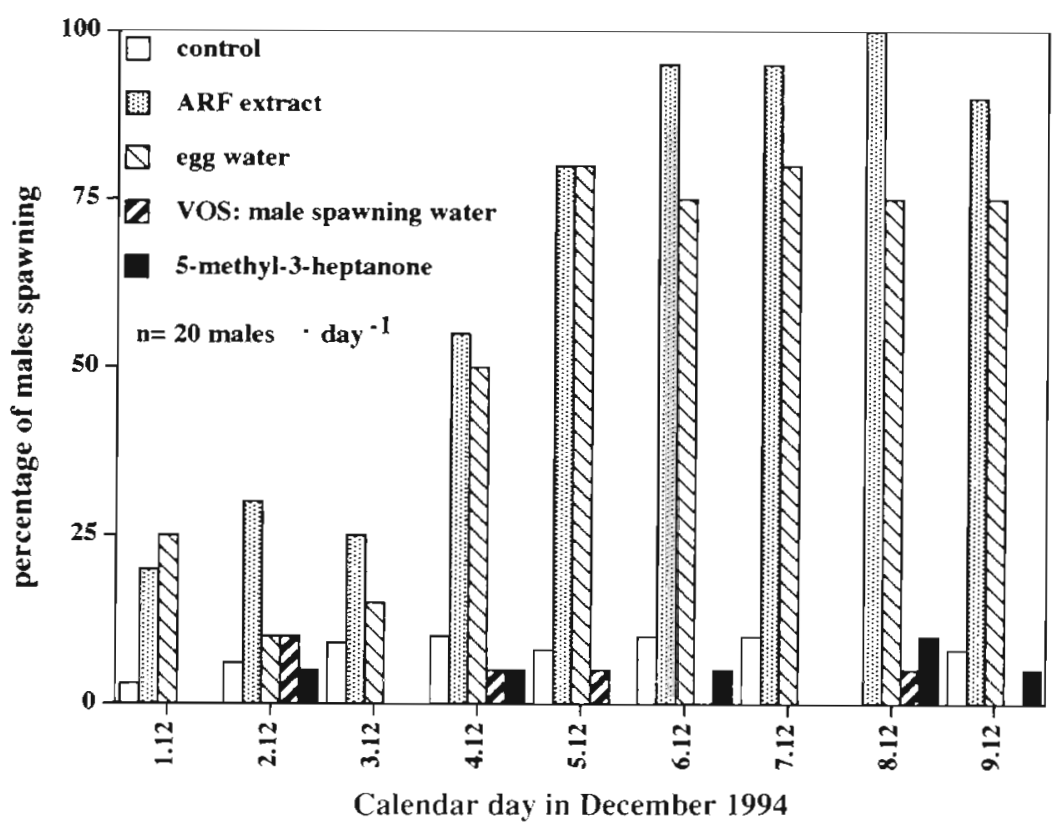

Fig. 1 Behavioural assays with gravid, isolated male Arenicola marina. Data represent the percentage of males releasing sperm upon exposure to various substances. Control: sea water; ARF-extract: A. marina female coelomic fluid extract of aqueous, non-volatile substances (see 'Material and methods'); egg water: supernatant of sea water into which gravid female $A$. manna had shed eggs (addition of 0.5 female equivalents); VOS: volatile organic substances extracted from a supernatant of male 'spawning water' (addition of 0.5 male equivalents); 5 -methy]-3-heptanone: $100 \mathrm{ng} \mathrm{l}^{-1}$ synthetic ketone. $\mathrm{n}=20$ males per treatment per day $=100$ males per experimental day males from East Sands, St. Andrews) but males increased activity (movement within the boxes) in a manner similar to that exhibited during release of sperm, a behaviour which could not be elicited by addition of sea water. Experiments with gravid males from the Eden Estuary undertaken in November 1994 revealed that sea water into which spawning females had actively released eggs (termed 'egg water') does induce males to shed gametes (Fig. 1). As with the addition of female culture water (no gametes released), no gametes were shed when $1 \mu \mathrm{l}$ and $5 \mu \mathrm{l}$ of the VOS extract from gravid females was added to ripe males (Fig. 1). In this case, 8 of 10 and 7 of 10 males (5 November 1994, Eden Estuary males) increased activity but no gametes were released over a period of $12 \mathrm{~h}$. Synthetic 5-methyl-3-heptanone (10 $\mathrm{ng} \mathrm{l}^{-1}$ and $\left.100 \mathrm{ng} \mathrm{l}^{-1}\right)$ also failed to induce spawning (Fig. 5) but produced a similar 'increase in activity' (data not shown) while control addition of acetone (used as solvent in VOS extraction, $10 \mu \mathrm{l}$ and $100 \mu \mathrm{ll}$ did not affect the males but produced a high mortality ( 8 of 10) within $24 \mathrm{~h}$. In contrast, the extract of non-volatile, water soluble substances prepared from gravid females (ARF, see Fig. 1) induced spawning in males at a level similar to the percentage reacting upon exposure to fresh 'egg water'.

As described above, female Arenicola marina shed eggs within the burrow prior to the release of gametes onto the surface of the beach by males Due to the absence of still gravid, unspawned female $A$. marina within the natural habitats at the time of the natural spawning in males (Hardege \& Bentley unpubl.) only a limited number of bioassays could be performed. In these experiments, Hardege \& Bentley (unpubl.) demonstrated that sea water samples into which males had released gametes ('spawning water') induced females to shed eggs regardless of whether sperm had been removed by centrifugation or not, indicating that a water-borne pheromone induced this reaction. Fig. 2 shows similar results but confirms that neither synthetic 5-methyl-3-heptanone nor the VOS extract from male spawning water induced a release of gametes in females.

Upon exposure to male 'spawning water' female Arenicola marina (East Sands 1993) in the U-tube bioassay system started pumping actively 16 of 8 on 30 October 1993; 5 of 8 on 31 October 1993 and again 5 of 8 on 31 
Fig. 2. Behavioural assays with gravid, isolated female Arenicola marina. Release of eggs upon exposure to samples obtained from spawning males. Data show mean $\pm \mathrm{SD}$ of the percentage of females releasing eggs upon exposure to various substances. Gametes were removed from male spawning water (see 'Materials and methods'\}. Addition of VOS was 0.1 male equivalent. All other substances as in Fig. 1. $n=20$ females per treatment, 3 replications of experiment on different days, data pooled

Fig. 3. Effects of exposure to extracts of VOS on irrigation behaviour (pumping activity) of grayid Arenicola marina females. Data show mean \pm SD of 3 replicates. Worms were monitored visually for signs of activity or release of gametes. hw: simulated high tide, no currents; incoming tide: $10 \mathrm{ml} \mathrm{min}{ }^{-1}$ sea water added after $30 \mathrm{~min}$ of low tide; low tide: low water level, surface exposed; male spawning water: gametes removed, 1.0 male equivalent added; VOS: addition of 1.0 male equivalent; 5-methyl-3heptanone: $100 \mathrm{ng}^{-1}$ synthetic ketone
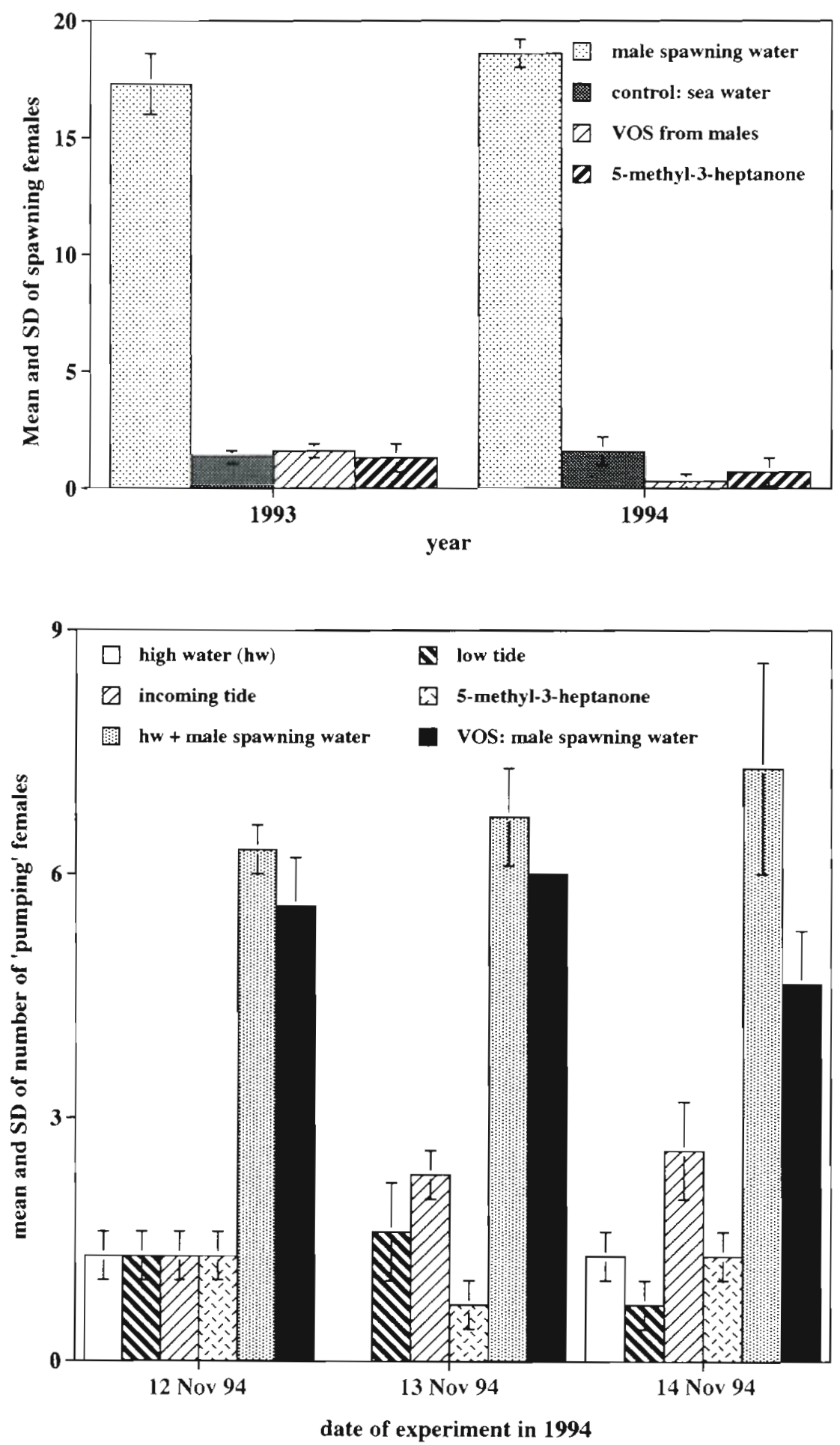

October 1993). Females started pumping within 2 min of initial exposure, indicating the existence of a waterborne signal showing the presence of ripe males. Experiments were repeated in 1994 with females from the Eden Estuary (St. Andrews), and worms were again exposed to a VOS extract obtained from male 'spawning water' and synthetic 5-methyl-3-heptanone. Fig. 3 shows that male spawning water and the volatile extract elicited a positive reaction but the synthetic ketone had no activity. Similarly, control additions of acetone and sea water produced no response. 
Behavioural assays with immature specimens collected from a juvenile site at East Sands, St. Andrews (October 1993) showed no reaction to any extract in either the U-tube assay system or upon exposure in isolated boxes (data not shown).

\section{Extraction and analysis of VOS}

Analyses of volatile organic compounds from coelomic fluid $(10 \mathrm{ml})$ were performed with males and juvenile worms starting in July 1993 and females starting in September 1993 (dates as in Table 1). Juvenile coelomic fluid contained only very low amounts of VOS. Male coelomic fluid from samples in August and September 1993 showed a slightly increasing number of worm-produced volatiles but still in very low con- centrations, whilst most of the detectable volatiles were also found in sea water controls. Similarly, coelomic fluid from developing females extracted in September 1993 contained only a very limited amount of worm-associated VOS (Table 2). As the natural spawning season approaches, the amount of VOS increases steadily: the analyses of coelomic fluid from gravid males and females taken 2 wk prior to spawning in the field are shown in Fig $4 \mathrm{a}, \mathrm{b}$. One of the major classes of compounds in extracts from both sexes is ketones; and, the sex pheromone of Platynereis dumerili, 5-methyl-3-heptanone, is detectable in ripe males of Arenicola marina (Fig. 4a, Table 2).

GC-MS analysis of samples collected from the 'sperm puddles' in the field (East Sands, 2 and 3 November 1993) showed (Fig. 5) that almost no wormrelated volatiles were detectable; most compounds
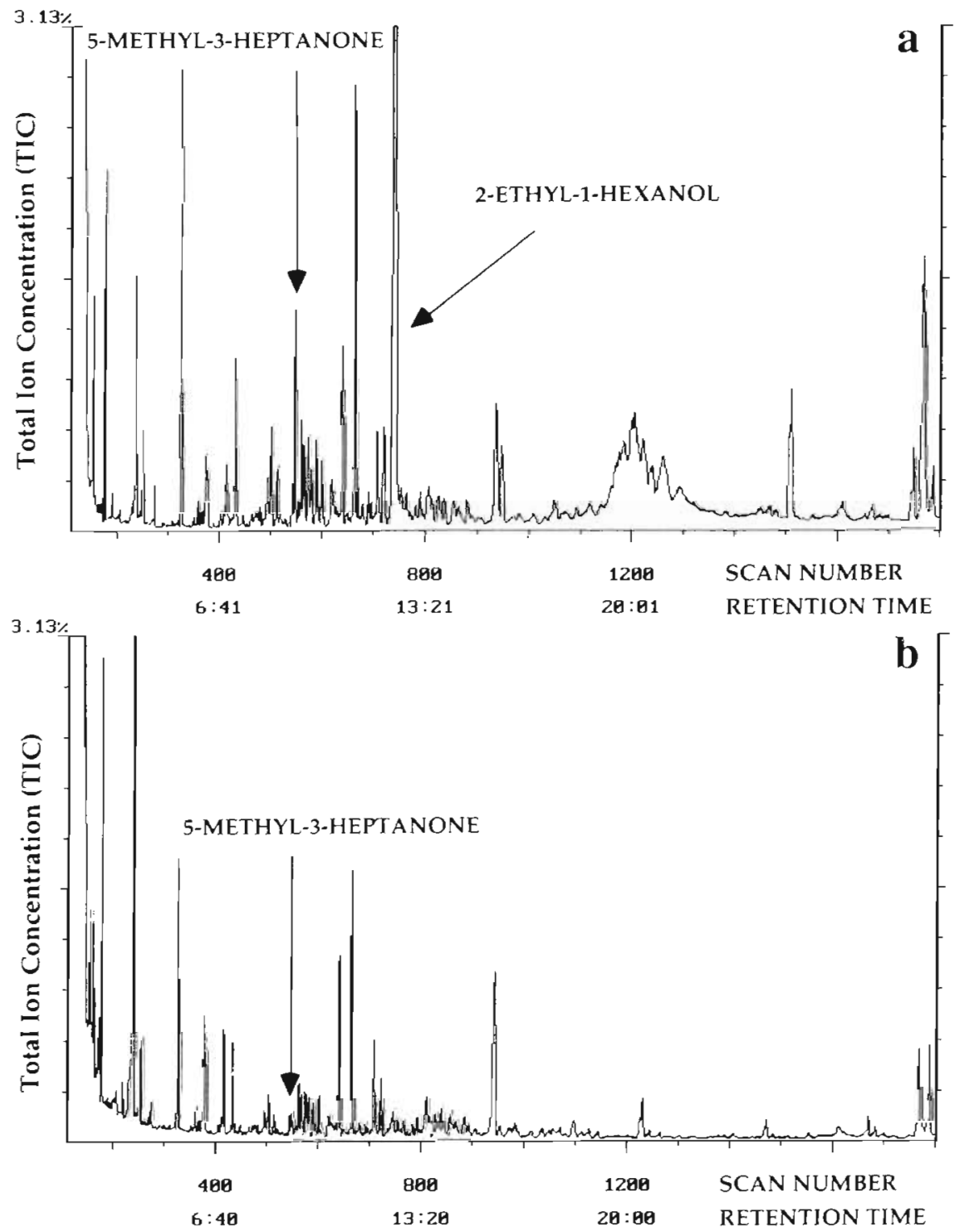

Fig. 4. Gas chromatographic analysis of volatile organic compound extract obtained via closed loop stripping extraction from (a) gravid Arenicola marina males collected from East Sands, St. Andrews (15 October 1993), supernatant of $10 \mathrm{ml}$ coelomic fluid $(\mathrm{n}=2$ males) and (b) gravid $A$. marina females collected from East Sands 115 October 1.993), supernatant of $10 \mathrm{ml}$ coelomic fluid ( $\mathrm{n}=2$ females). See 'Materials and methods' for centrifugation and $\mathrm{GC}$ conditions 
Table 2. Volatile organic substances isolated from the coelomic fluid of male and female Arenicola marina and 'sperm puddles' of male A. marina. Dates of collection are shown

\begin{tabular}{|c|c|c|c|c|}
\hline & $\begin{array}{c}\text { Male } \\
\text { Aug 1995) }\end{array}$ & $\begin{array}{l}\text { Female } \\
\text { (Oct 1995) }\end{array}$ & $\begin{array}{c}\text { Male } \\
\text { (Oct 1995) }\end{array}$ & $\begin{array}{l}\text { Puddles } \\
\text { (Nov 1995) }\end{array}$ \\
\hline 2.4.5-trimethylhexane & - & + & + & - \\
\hline 2.3.5-trimethylhexane & - & + & + & - \\
\hline 2.5-dimethylheptane & - & + & + & - \\
\hline 5-methyl-3-heptane & + & + & + & + \\
\hline 4 -methyloctane & - & + & + & - \\
\hline 2-methyloctane & - & + & + & - \\
\hline 3.4.5-trimethylheptane & - & + & - & - \\
\hline 5-methylnonane & + & + & + & - \\
\hline 4-methyldecane & + & + & - & - \\
\hline 5-methyldecane & + & + & + & - \\
\hline 5-methylundecane & - & + & + & - \\
\hline 2-heptanone & + & - & + & - \\
\hline 4-methyl-2-hexanone & + & - & - & - \\
\hline 5-methyl-3-hexanone & - & + & + & - \\
\hline 2.4-dimethyl-3-hexanone & - & + & + & - \\
\hline 2-methyl-4-heptanone & - & + & - & - \\
\hline 2-methyl-3-heptanone & - & + & - & - \\
\hline 5-methyl-3-heptanone & - & + & + & - \\
\hline 3-nonanone & + & + & + & - \\
\hline 3-methyl-4-nonanone & - & + & + & - \\
\hline 2-undecanone & + & + & + & - \\
\hline geraniol & - & + & - & - \\
\hline geranylacetone & - & + & - & - \\
\hline 2-ethyl-1-hexanol & - & + & + & - \\
\hline 9-decene-1-ol & + & + & + & - \\
\hline 2-nonene-1-ol & - & + & - & - \\
\hline 4-methyl-3-heptene & - & - & + & + \\
\hline 7-methyl-1-octene & - & - & + & + \\
\hline 7 -tetradecene & + & + & - & - \\
\hline 1 -hexadecene & - & + & - & - \\
\hline 1-heptadecene & - & + & - & - \\
\hline 4-hydroxy-4-methylpentanone & le - & + & + & + \\
\hline 3.7-dimethyl-1.3.6-octatriene & - & + & - & + \\
\hline 3-carene & - & + & + & + \\
\hline 6-methyl-5-heptene-2-one & - & + & - & _- \\
\hline
\end{tabular}

identified are typical constituents of St. Andrews area sea water samples. The 5-methyl-3-heptanone is also no longer detectable and the extract does not contain any ketones. Sperm puddles were collected with a pipette directly from the beach as soon as they appeared after the tide receded. As the sperm is released onto the surface of the beach it is instantly diluted with sea water so that VOS might have been washed out prior to collection of the sample. Other more likely explanations for the lack of VOS in water samples from the beach are that these compounds were emitted prior to the release of gametes or that they are trapped within the oily sperm puddles. As the sperm was removed from the samples prior to extraction (via centrifugation) the VOS might have been trapped in the lipid rich sperm fraction.

VOS were also extracted from 'spawning water', sea water into which gravid males had released gametes (Iernoved via centrifugation, see 'Materials and methods') in the laboratory. As described by Pacey \& Bentley (1992) a few of the lugworms cultured in isolation in the laboratory spawn spontaneously without contact with conspecifics at around the natural spawning season. Fig. 6 shows the $\mathrm{GC}$ analysis (GC conditions differ-
Fig. 5. Gas chromatographic analysis of VOS extracted via closed loop stripping from 'sperm puddles' collected from the surface of the beach at low tide (November 1993) at East Sands. GC conditions as in Fig. 4

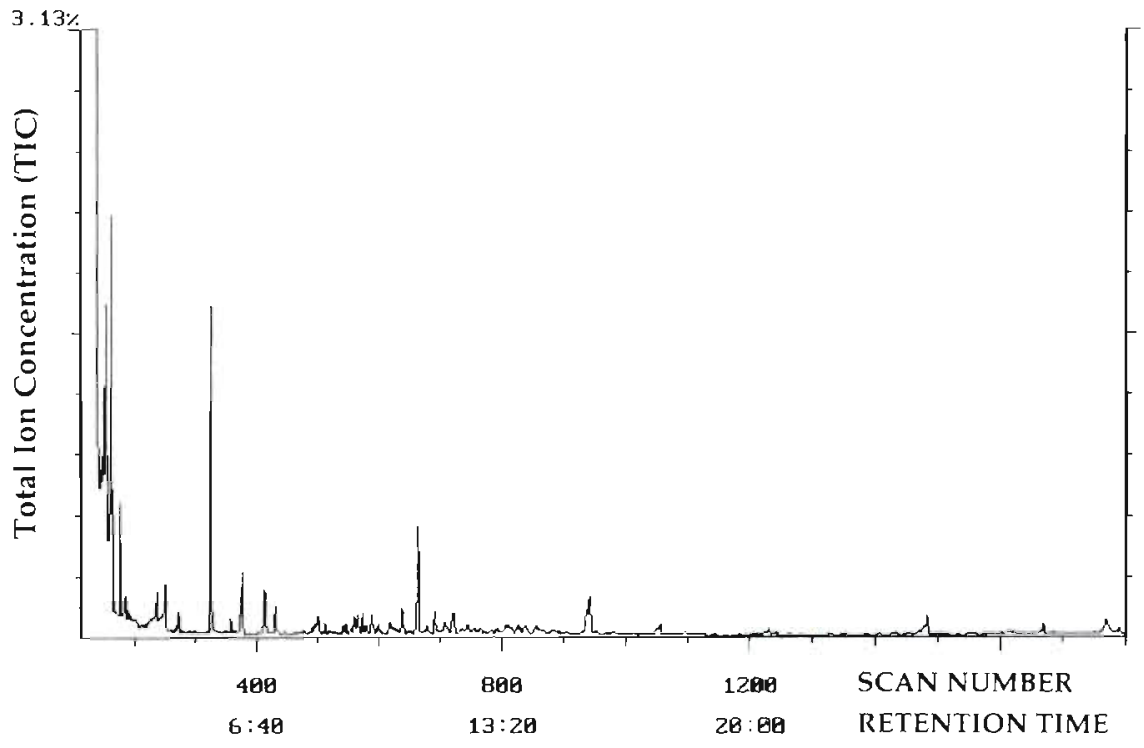




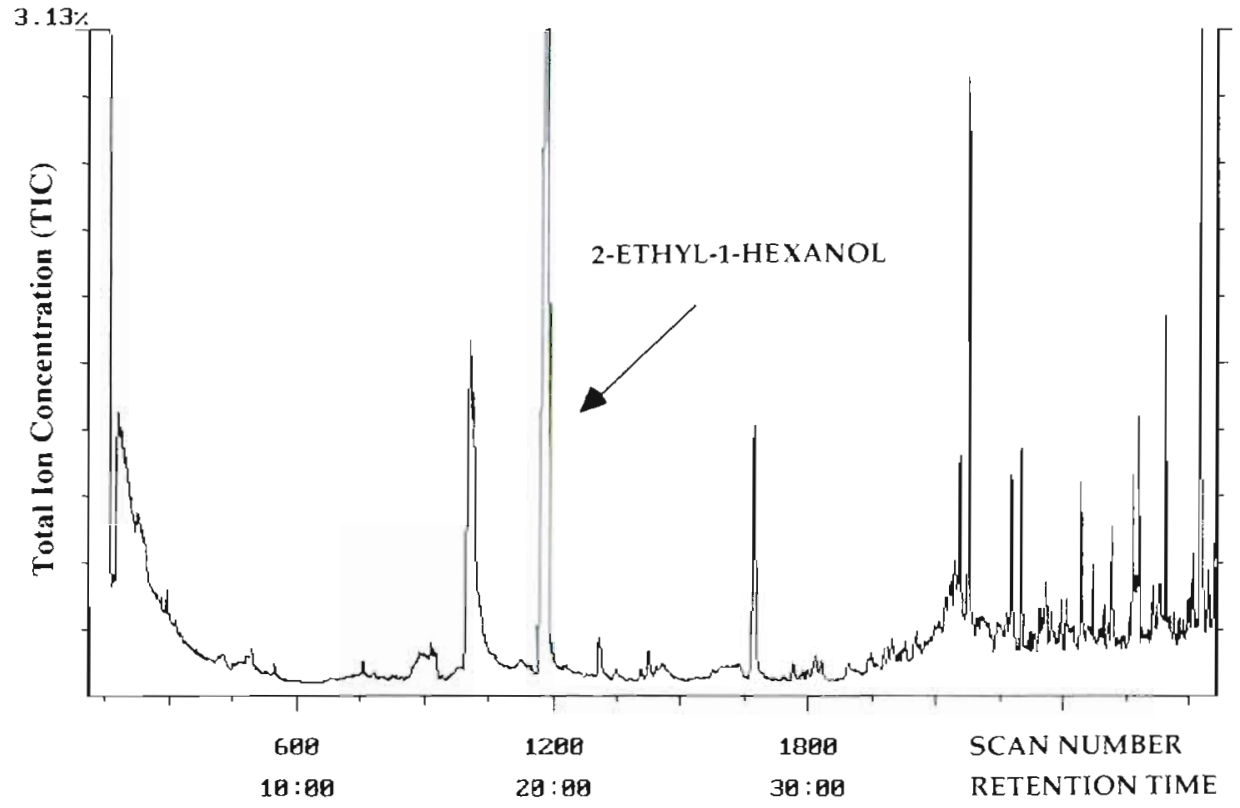

Fig. 6. Gas chromatographic analysis of VOS extracted via closed loop stripping from sea water into which 10 gravid Arenicola marina males from Eden Estuary, St. Andrews, Scotland had released gametes. Prior to extraction gametes were removed via centrifugation ent to Figs, 4 \& 5, see legend) of a sample obtained from 10 spawning males (Eden Estuary). Similar to the analysis of the extraction of water from sperm pools collected on the beach at East Sands, the analysis of this sample shows only a minor peak at the retention time of the nereid pheromone 5-methyl-3-heptanone. The major volatile compound in the coelomic fluid of gravid males, 2-ethyl-1-hexanol (Fig. 4a, retention time 12.2 min, spectrum no. 745), also represents the dominant VOS released by spawning male Arenicola marina.

\section{DISCUSSION}

In a number of species of marine polychaete, the existence of sex pheromones has been postulated to control both the induction of the release of gametes and the stimulation of specific reproductive behaviours, such as the nuptial dance of nereids. In Platynereis dumerilii the nuptial dance is triggered by a volatile ketone, 5-methyl-3-heptanone (Zeeck et al. 1988), which was extracted via a closed loop stripping technique (Grob \& Zürcher 1976) and identified by means of GC-MS analysis. The nuptial dance is followed by the release of gametes of both partners due to further pheromonal signals of non-volatile character but, to date, still unknown chemical nature. 5-methyl3-heptanone is one of the major volatile constituents of the coelomic fluid of ripe Arenicola marina males but elicited no behavioural changes in either sex. Although $A$. marina and nereids are considered to be broadcast spawners, their reproductive behaviour is very different. Nereids such as $P$. dumerilii reproduce whilst swimming freely in the water column. Here, the ketone is used to achieve recognition of the partner of the opposite sex, but functions mainly as an arrestant towards specimens passing close to the source of the signal. It elicits the 'nuptial dance' behaviour, i.e. swimming in circles of continually decreasing diameter which subsequently leads to the release of gametes due to additional pheromonal signals. In contrast, in $A$. marina both partners remain in their burrows and only the male gametes are shed onto the beach and into the water column.

In Arenicola marina a high fertilization rate in the field depends on the transport of spermatozoa into the burrows of the females. This process is correlated with the incoming tide during the spring tides; field studies at East Sands, St. Andrews (Williams et al. 1996) revealed the precise timing necessary. Dilution of spermatozoa by the incoming tide is so fast that fertilization success requires an active transport mechanism for sperm by the females. This is achieved through the pumping of sea water through the burrows by the female (Hardege \& Bentley unpubl.). This burrow irrigation behaviour ensures transport of a few $\mathrm{ml}$ of sea water containing spermatozoa towards the eggs that have already been released but are retained in the burrow. The present data show that an extract of VOS from male spawning water can induce this behaviour, indicating that female A. marina 'detect' the presence of spawned male gametes via VOS. Although the nereid sex pheromone 5-methyl-3-heptanone is detectable in A. marina, this substance does not represent the natural 'pumping factor' The substance has not yet been chemically characterised, but Figs. $4 \& 5$ show the occurrence of 1 major VOS peak in male 
spawning water. This substance, 2-ethyl-1-hexanol, is not detectable in immature specimens and occurs only in traces in gravid, non-spawning animals but represents the major VOS of the biologically active 'spawning water' and is therefore likely to represent the natural sex pheromone. For definitive proof, biological assays with synthetic material have to be undertaken during the next spawning season.

The direct correlation between the 'state of maturity' of Arenicola marina and the occurrence of the sex pheromonal activity will also form the basis for further investigations into the relationship between the spawning hormone 8,11,14-eicosatrienoic acid (Bentley \& Pacey 1992) and the control of the production of sex pheromones. In vivo injection of the hormone into gravid males causes the release of activated spermatozoa within 45 to 60 min (Pacey \& Bentley 1992) and this can be used as a model to study hormone-pheromone interaction in marine invertebrates.

In general, there is an increase in the number and amount of VOS found within the coelomic fluid during maturation in both sexes. The VOS extracts obtained from gravid animals just prior to the natural spawning season are chemically quite similar to those from nereids (see Zeeck et al. 1988) but also to VOS extracted from other marine organisms, e.g. in the Atlantic oyster Crassostrea virginica (Josephson et al. 1985), numerous insects (Bestmann \& Vostrowsky 1982), mammals (Albone \& Shirley 1984), and even human urine (Ellin et al. 1974) Some of the identified substances from Arenicola marina have been described as pheromones in insects, e.g. a number of ketones function as alarm pheromones in ants (Shorey 1977), as well as in mammals such as the reindeer Rangifer tarandus (Andersson 1977). This demonstrates the conservative chemical character of odour compounds forming the aroma bouquets in both the aquatic and terrestrial milieu. Volatile organic substances are used as semiochemicals in numerous organisms and are involved in the control of all key biological behaviours, and their role in marine invertebrates had been largely underestimated. The present investigation describes for the first time such biological activity in the control of spawning in an iteroparous polychaete. The described results once again fit the theory (Thiessen 1977) that chemical signal molecules are not synthesised de novo in a given species but have been quite stable throughout evolution. A mixture of different compounds within an odour bouquet and/or the use of isomers and enantiomers can guarantee species specificity of chemical signalling without the biosynthetic problems of a de novo synthesis.

As with nereid polychaetes (Hardege 1992), the VOS extracts never induced the active release of gametes in Arenicola marina. Recent investigations (Hardege \&
Bentley unpubl.) showed the existence of non-volatile, polar and water soluble chemical signals inducing the release of gametes in both sexes, but to date their chemical nature has not been determined. Fig. 2 also shows that this 'gamete release' pheromone is associated with the presence of gametes in the sea water: water from a culture tank with gravid females failed to induce spawning. One can hypothesise a structureactivity relationship of chemical signals in marine organisms with lipophilic, volatile substances used in long range communication, e.g in nereid polychaetes (Zeeck et al. 1988), and sex pheromones described to be water soluble and of non-volatile character used in short range communication or direct contact sex (Hardege et al. 1994), such as the contact sex pheromone in the marine rotifer Brachionus plicatilis, a $29 \mathrm{kDa}$ glycoprotein (Snell et al. 1995).

Further work with Arenicola marina will focus on the improvement of the 'pumping activity' bioassay to see whether the observed biological activity of the crude extract of VOS can be ascribed to a single substance and, if so, to subsequently identify this pheromone using synthetic material of the main VOS, 2-ethyl-1hexanol. Similarly to the situation in nereids, the chemical communication during reproduction is achieved via a bouquet of signal molecules, and future work will therefore also focus on the identification of the non-volatile compounds of the pheromone bouquet. To date, our knowledge on the role of chemical signals in the timing of the reproduction in A. marina is still incomplete, but present results represent a first step towards an understanding of the mechanisms involved in the spectacular occurrence of mass spawning of this polychaete.

Acknowledgements. The authors thank F. Prisznitz for assistance in GC-MS measurements and Prof. Dr E. Zeeck, Unuversity of Oldenburg, Germany for kindly providing access to his GC-MS system. We also thank G. Watson and M. Williams for help with collection and maintenance of the lugworms. The authors gratefully acknowledge support from the Natural Environment Research Council (NERC GR3/8628).

\section{LITERATURE CITED}

Agosta WC (1992) Chemical communication: the language of pheromones. Scientific American Library Series, New York

Albone ES, Shirley SG (1984) Mammalian semiochemistry. The investigation of chemical signals between mammals J Wiley \& Sons Ltd, Chichester

Andersson G (1977) Volatile ketones from the preorbital gland of the reindeer, Rangifer tarandus. J Chem Ecol 5 . $629-634$

Bentley MG, Clark S, Pacey AA (1990) The role of arachidonic acid and eicosatrienoic acids in the activation of spermatozoa in Arenicola marina L. (Annelida: Polychaeta). Biol Bull 178:1-9 
Bentley MG, Hardege JD (1996) The role of a fatty acid hormone in the control of reproduction in the male lugworm. Invertebr Reprod Dev (in press)

Bentley MG. Pacey AA (1992) Physiological and environmental control of reproduction in polychaetes. Oceanogr Mar Biol A Rev 30:443-481

Bestmann HJ, Vostrowsky O (1982) Insektenpheromone Naturwissenschaften 69:457-471

Boilly-Marer Y, Lassalle B (1978) Electrophysiological responses of heteronereids stimulated with sex pheromones (Annelida, Polychaeta). J Exp Zool 205:119-124

Boland W (1989) Application of molecular modelling techniques to pheromones of the marine brown algae Cutleria multifida and Ectocarpus siliculosus (Phaeophyceae), metalloproteins as chemoreceptors? Z Naturforsch Sect C J Biosci 44:829-837

Boland W, König WA, Krebber R, Müller DG (1989) 143. Separation of enantiomeric algae pheromones and related hydrocarbons by gas-liquid chromatography on modified cyclodextrins as chiral stationary phases. Biosynthetic relevance of racemic by-products. Helv Chim Acta 72:1288-1299

Coll JC, Leone PA, Bowden BF, Carroll GM, Heaton A, de Nys R, Maida M, Alino PM, Willis RH, Babcock RC, Florian $Z$, Clayton $M N$, Miller RL, Alderslade PN (1995) Chemical aspects of mass spawning in corals. II. (-)-Epithunbergol, the sperm attractant in the eggs of the soft coral Lobophytum crassum (Cnidaria: Octocorallia). Mar Biol 123:137-143

Duncan A (1960) The spawning of Arenicola marina (L.) in the British Isles. Proc Zool Soc Lond 134:137-156

Ellin RI, Farrand RL, Oberst FW, Crouse CL, Billups NB, Koon WS, Musselmann NP, Sidell FE (1974) An apparatus for the detection and quantification of volatile human effluents. J Chromatogr 100:137-152

Grob K, Zürcher F (1976) Stripping of trace organic substances from water. Equipment and procedure. J Chromatogr 117:285-294

Hardege JD (1992) Verhaltensmodifizierende Naturstoffe (Pheromone) bei der Fortpflanzung von Nereiden (Annelida, Polychaeta). $\mathrm{PhD}$ thesis, University of Oldenburg

Hardege JD, Bartels-Hardege HD, Yang Y, Wu BL, Zhu MY, Zeeck E (1994) Environmental control. of reproduction in Perinereis nuntia var brevicirrus. J Mar Biol Ass UK 74: 903-918

Howie DID (1959) The spawning of Arenicola marina (L.). I. The breeding season. J Mar Biol Ass UK 38:395-406

Howie DID (1961a) The spawning of Arenicola marina (L.) II Spawning under experimental conditions. J Mar Biol Ass UK 4 1:127-144

Howie DID (1961b) The spawning of Arenicola marina (L.) III. Maturation and shedding of the ova. J Mar Biol Ass UK 41 : $771-783$

Howie DID (1963) Experimental evidence for the humoral stimulation and ripening of the gametes and spawning in the polychaete Arenicola marina (L.). Gen Comp Endocr $3: 660-668$

This article was submitted to the editor
Howie DID (1984) The reproductive biology of the lugworm Arenicola marina $\mathrm{L}$. In: Fischer $A$, Pfannenstiel $\mathrm{HD}$ (eds) Polychaete reproduction. Fortschritte der Zoologie, 29. G. Fischer Verlag, Stuttgart, p 247-263

Jaenicke L (1977) Sex hormones of brown algae. Naturwissenschaften 64:69-75

Jaenicke L, Boland W (1982) Sexualstoffe und ihre Rezeption im Sexualzyklus mariner Braunalgen. Angew Chemı 94: $655-724$

Josephson DB, Lindsay RC, Stuiker DA (1985) Volatile compound characterizing the aroma of fresh Atlantic and Pacific oysters. J Food Sci 50:5-9

Machlis L, Nutting WH, Williams MW, Rapoport H (1966) Production, isolation, and characterization of sirenin. Biochemistry $5: 2147-2152$

Meijer L (1979) Hormonal control of oocyte maturation in Arenicola marina L. (Annelıda, Polychaeta). I. Morphological study of oocrte maturation. Dev Growth Differ 21: $303-314$

Müller DG, Gassmann G, Marner FJ, Boland W, Jaenicke L (1982) The sperm attractant of the marine brown alga Ascophyllum nodosum (Phaeophyceae). Science 218: $1119-1120$

Müller DG, Schmid CE (1988) Qualitative and quantitative determination of pheromone secretion in female gametes of Ectocarpus siliculosus (Phaeophyceae). Biol Chem Hoppe-Seyler 369:647-653

Neumann C, Boland W (1990) Stereochemical studies on algal pheromone biosynthesis: a model study with the flowering plant Senecio isatideus (Asteraceae). Eur J Biochem 191: $453-459$

Pacey AA, Bentley MG (1992) The fatty acid 8,11,14eicosatrienoic acid induces spawning in the male lugworm Arenicola marina. $J$ Exp Biol 173:165-179

Pommerville J (1988) Effects of analogs of the fungal sexual pheromone sirenin on male gamete motility in Allomyces macrogynus. Plant Physiol 88:139-142

Shorey HH (1.977) Evolution of pheromonal communication. In: Animal communication by pheromones. Academic Press, New York, p 117-121

Snell TW, Rico-Martinez R, Kelly LN, Battle TE (1995) Identification of a sex pheromone from a rotifer. Mar Biol 123: $347-353$

Thiessen DD (1977) Thermoenergetics and the evolution of pheromone communication. In: Sprague JM, Ebstein AN (eds) Progress in polycobiology and physiological psychology, Vol 7. Academic Press, New York, p 92-191

Williams ME, Bentley MG, Hardege JD (1996) Assessment of field fertilisation success in the infaunal polychaete Arenicola marina (L.). Invertebr Reprod Dev (in press)

Zeeck E, Hardege JD, Bartels-Hardege $H$, Wesselmann $G$ (1988) Sex pheromone in a marine polychaete: determination of the chemical structure. J Exp Zool 246:285-292

Zeeck E, Hardege JD, Willig A, Krebber R, König WA (1992) Preparative separation of enantiomeric polychaete sex pheromones. Naturwissenschaften 79:182-183

Manuscript first received: October 19, 1995

Revised version accepted: April 22, 1996 